\title{
Viver na rua em Paris: Do desprezo ao reconhecimento
}

Lucas Graeff
(UNILASALLE)

Brasileiro, psicólogo e dispondo de algumas experiências de pesquisa etnográfica junto às camadas desfavorecidas da população de Porto Alegre/RS (Graeff 2002, 2007), decidi estudar as maneiras pelas quais um "país rico" dá conta de seus "pobres"1. Durante quatro anos, dois dos quais dedicados a um trabalho de campo de caráter etnográfico, procurei compreender por que as formas de organização das sociedades contemporâneas não conseguem resolver uma das consequências paradoxais do crescimento econômico, a saber, a exposição de milhares de homens, mulheres e crinças a condições de vida miseráveis, estejam elas no interior ou nas margens das grandes cidades. Interessei-me, sobretudo, pelas razões que levam essas pessoas a serem desrespeitadas pelos outros: por que, além de se verem obrigadas a lançar mão de subterfúgios diversos para garantir sua sobrevivência, tais pessoas precisam enfrentar olhares reprovadores e reações de repulsa frente aos demais moradores da cidade? Por que são elas consideradas "descartáveis" pelos programas sociais ${ }^{2}$ e representadas como "sujas", "loucas", "perigosas" ou "coitadas" pela população em geral ${ }^{3}$ ?

Neste artigo, apresento alguns aspectos do estudo etnográfico realizado em Paris, França, e proponho uma reflexão sobre essas situações que podem ser definidas como "experiências de desrespeito social" (Honneth 2006). O artigo se organiza analiticamente a partir de uma transformação, operada em termos de construção de objeto de estudo, que se deu a partir de uma mobilização coletiva de SDF (Sem Domicílio Fixo) em Paris ${ }^{4}$. Antes desse evento, meu trabalho de pesquisa se concentrava em grupos de pessoas vivendo em grupo ou individualmente nas ruas de Paris e priorizava o dia-a-dia dos meus interlocutores - suas dificuldades relativas à domesticação do espaço urbano, por exemplo. Após a mobilização, passei a me questionar sobre as possibilidades de conjurar as expectativas sociais negativas que pesam sobre o "corpo precário" (Dambyyant-Wargny 2006) e, 
sobretudo, sobre as situações de "desprezo social" (Honneth 2006) ressentidas por todos os meus interlocutores. Para além de uma luta pela sobrevivência, será que a vida na rua pode ser definida como uma luta contra o desprezo social?

A fim de responder a essa questão, começo o artigo apresentando os limites e as possibilidades da minha pesquisa etnográfica em terra estrangeira: por onde começar uma pesquisa de campo em espaço urbano quando a cidade inteira, seus espaços e seus habitantes produzem estranhamentos sucessivos? Como estabelecer relações de confiança e reciprocidade com pessoas em situação de rua na capital francesa, sem as quais as situações de desprezo social não poderiam ser documentadas?

Em seguida, faço algumas considerações sobre as relações entre a aparência corporal dessas pessoas e as situações de desprezo vividas por elas no dia-a-dia: como definir uma experiência ou sentimento de "desrespeito social"? Como o "corpo precário" (Dambuyant-Wargny 2006), esse corpo transformado e maltratado pelas condições de existência na rua, ilustra as experiências de humilhação e de transformação identitária dos pesquisados?

Por fim, apresento o evento que transformou o meu objeto de estudo em Paris: uma mobilização social ocorrida no final de 2006, onde alguns de meus interlocutores conseguiram ser reconhecidos como cidadãos legítimos lutando por seus direitos. Como essa nova condição repercute nas maneiras pelas quais uma pessoa em situação de rua em Paris é reconhecida socialmente? Os referentes identitários que emergiram durante a mobilização contribuíram a reduzir as experiências de desrespeito vinculadas a outras esferas de suas relações intersubjetivas?

\section{LIMITES E POSSIBILIDADES DE UMA ETNOGRAFIA JUNTO A PESSOAS EM SITUAÇÃO DE RUA, EM PARIS}

Minha chegada a Paris ocorreu no dia 11 de maio de 2006. Falando um francês básico e instalado de maneira precária em um pequeno hotel da cidade, aguardei três semanas antes de iniciar minha pesquisa etnográfica junto a grupos e indivíduos em situação de rua na cidade. Com o objetivo de testemunhar como essas pessoas vivem e sobrevivem às condições miseráveis de existência nas quais elas se encontram, não coloquei outros limites ao meu campo etnográfico que aqueles que me foram impostos pelos elementos sócio-culturais da cidade. A língua, por exemplo: antes de começar uma conversa com um informante potencial, foi necessário desenvolver uma compreensão razoável do francês. Assistir televisão, ler jornais, me aventurar pelas ruas da cidade escutando conversas cruzadas. Todo material linguístico vinha a contribuir para o meu processo de inserção na cultura francesa.

Além da língua, tive que descobrir a cidade em suas lógicas e seus fluxos. Acostumado com as ruas axiais de minha cidade natal, Porto Alegre, estranhava as curvas e diagonais que cortam os bairros de Paris, assim 
como as "quadras" triangulares ou em forma de trapézio, que tornavam minhas caminhadas longas ou curtas ao acaso. Ao utilizar o metrô, descobri a curiosa sensação de surgir, desorientado, em uma região desconhecida da cidade. Sem saber para onde ir, hesitei muitas vezes entre pedir informações e procurar mapas de ônibus ou do bairro a fim de continuar meu percurso. Com o tempo, cheguei a comprar uma pequena bússola, utilizada especialmente nesses casos de passagem do subterrâneo à superfície.

A fim de dar conta dos limites sócio-culturais que encontrava, recorri às técnicas e premissas da antropologia social: a comparação e a observação. Tais técnicas e premissas supõem que "os comportamentos das pessoas e as construções sociais devem ser apreendidas desde sua própria cultura, para só então conquistar um plano comparativo e uma perspectiva generalizante, que transcende a diferença particularizada e relativa" (Eckert 1998:95). Colocando-me em relação imediata com a população-alvo, procurei estabelecer relações de reciprocidade com meus interlocutores para, uma vez "vivendo entre os nativos" (Malinowski 1976), apreender o seu ponto de visa sobre as condições de vida nas quais se encontravam.

$\mathrm{O}$ ponto de partida da pesquisa foi o rio Sena, que corta a cidade de Paris de leste à oeste 5 . Percorrendo-o do centro da cidade até o lado leste, onde está localizada a torre Eiffel, fiz contato com um primeiro grupo. Em número de três a cinco pessoas (de acordo com a época da pesquisa), esse primeiro grupo me serviu de referência durante toda pesquisa etnográfica. Mais tarde, no decorrer dos meses de maio de 2006 e abril de 2008, período no qual a pesquisa foi desenvolvida, encontrei mais de uma centena de pessoas vivendo nas rua parisienses. Porém, consegui estabelecer contatos sistemáticos apenas com cinquenta e uma delas. O que explica essa dificuldade? Seria uma barreira ligada à língua ou a questões de ordem cultural? Como transformar tal dificuldade de ordem prática em uma questão de pesquisa?

No que concerne aos obstáculos relativos ao estabelecimento de relações duradouras, formulei a hipótese de que não se tratava de um problema localizado, mas de uma dificuldade característica da população estudada. Com o tempo, descobri que algumas pessoas vivendo nas ruas de Paris podiam passar desapercebidas frente ao pesquisador, posto que nem todas se vestem com roupas usadas ou carecem de cuidados relativos a sua higiene pessoal (Gaboriau 2004). Em segundo lugar, descobri que as pessoas em situação de rua, em Paris, relutam geralmente a participar de pesquisas, visto que eles temem que um trabalho de investigação científica venha tornar pública a sua condição de vida atual ${ }^{6}$. Além disso, algumas das pessoas pesquisadas receavam que os dados de pesquisa pudessem se transformar em material para uso da polícia, colaborando assim para colocá-las na cadeia ou, no caso de imigrantes ilegais, para sua expulsão do território7. Um último elemento contribuindo para a labilidade das relações estabelecidas com meus informantes diz respeito às práticas repressivas sazonais da Prefeitura de Paris frente à população de rua: tolerante durante o inverno, o Município realiza evacuações sistemáticas a partir do momento em que as temperaturas sobem acima de zero ${ }^{8}$. Como resultado, mesmo conseguindo estabelecer relações de proximidade com meus interlocutores, nada garantia que eu iria encontrálos no dia seguinte. 
Os limites e possibilidades de minha pesquisa de campo começaram a se definir a partir desses obstáculos e situações práticas, descobertos sucessivamente durante os dois anos de pesquisa. Mais precisamente, as primeiras questões de investigação surgiram a partir das dificuldades encontradas no dia-a-dia do trabalho etnográfico. No que tange às práticas de higiene e de moradia das pessoas pesquisadas, por exemplo: é sempre melhor ser discreto, procurando apagar as "marcas corporais da miséria" (Dambuyant-Wargny 2006), a fim passar desapercebido frente aos poderes públicos e aos demais cidadãos? O que está implicado nesse esforço sistemático visando tornar o corpo aceitável ou invisível ao olhar dos outros?

\section{VIVER NA RUA EM PARIS: EXPERIÊNCIAS DE SOBREVIVÊNCIA E DE DESPREZO SOCIAL}

A partir dos limites e obstáculos encontrados em campo, encontrei diversos grupos e indivíduos vivendo suas vidas sob condições deploráveis de existência; pessoas com dificuldades de se proteger do frio, da chuva, da poluição urbana e de outras formas de violência ${ }^{9}$, assim como de encontrar lugares onde se alimentar, limparse e dormir com segurança e privacidade. Nesse sentido e num primeiro momento, o universo da rua em Paris surgiu como uma luta cotidiana pela sobrevivência, ou seja, pelas necessidades mais elementares relacionadas à integridade física e moral (Honneth 2009).

Com o objetivo de apresentar como a vida das pessoas pesquisadas se inscreve nessa luta pela sobrevivência, apresentarei trechos de meu diário de campo. Reorganizados em relação ao tema deste artigo e às questões que nortearam a minha prática de pesquisa em terra estrangeira, tais trechos ganham a forma de "sequências etnográficas"10:

Sequência 1: Dia 2 de novembro de 2006. Eu estou na companhia de Dominique e Arteck ${ }^{11}$, que se encontram num porto do rio Sena conhecido pelo nome "Port du Gros Caillou". Faz um frio difícil de tolerar para mim. Ao frio, soma-se o barulho dos carros, que não cessam de passar perto de onde nos encontramos. Nessas circunstâncias, sou tomado pelo sentimento de que o corpo ocupa um lugar central na minha pesquisa. Mas como dar conta dele? Basta estar ao lado de Dominique e Arteck para sentir o que eles sentem? Não seria preciso completar a minha própria experiência corporal com questões relativas às sensações dos meus informantes? Enquanto penso nessas questões, observo os dois homens. Dominique se protege do frio com dois casacos grossos, um edredom e um pedaço de pano servindo de echarpe, com o objetivo de proteger o pescoço. Na cabeça, uma touca de lã. Arteck, por sua vez, se contenta de um único casaco, um edredom e um boné. Além disso, eles montaram uma fogueira à base de tijolos, papel e gravetos, que serve para aquecer o vinho rosé com açúcar que eles não cessam de tomar. Quanto aos abrigos onde eles vivem, trata-se de duas estruturas paralelepipédicas, ambas construídas com as placas de alumínio que a prefeitura de Paris costuma utilizar para delimitar áreas de passagem de pedestre ou de construção. Após esse instante de observação, decido questionar meus informantes sobre o que eles fazem para suportar o frio parisiense. Dominique, o único francês do grupo, toma a palavra e responde por Arteck, seu companheiro polonês: "A gente se vira", diz. "Tu vistes o nosso abrigo? Faz um calorzinho legal lá dentro." Eu pergunto por que eles não ficam lá dentro durante dias como o de hoje, frio e ventoso: "Não, não é possível passar o dia todo enfurnado num abrigo, Lucas. Eu te entendo. Pra ti, o inverno é muito difícil. Pode até ser que em Porto Alegre faça frio, mas não como aqui. Quando tu sais pela manhã e ta fazendo abaixo de zero, a tua mão arde de dor, tua cara congela. Tu tens que colocar luvas, manta, touca. E às vezes não serve pra nada tudo isso... 
Mas no final das contas, a gente se acostuma. É mais fácil pra gente, que já é daqui. A nossa vida é assim. A gente se acostuma.

A luta contra o frio se impôs como a primeira de minhas interrogações sobre as experiências corporais das pessoas que estudei em Paris. Com o tempo, comecei a descobrir outras dimensões dos esforços visando à integridade física e moral: dormir, alimentar-se, urinar, defecar, tomar banho, lavar o corpo e seus orifícios. No universo da rua, todas essas atividades de base causam mal-estar. Primeiro, em razão de dificuldades práticas. Onde? Quando? Como? Em seguida, pela estigmatização de cada um desses gestos ${ }^{12}$. Dormir na rua, escovar os dentes em uma fonte pública, comer um sanduíche sentado na calçada, defecar atrás de um muro: tais práticas são consideradas "fora do lugar" e, portanto, inapropriadas.

A esse respeito, a sequência 2 apresenta uma discussão entre uma passante e um de meus informantes quando eles decidiam urinar num canteiro, atrás de um muro ou no rio Sena:

Sequência 2: Dia 16 de julho de 2007. Estou em companhia de um grupo SDF instalados em um terreno baldio ao lado do canal Saint-Martin. Inúmeras garrafas de cerveja e copos de plástico contendo pequenas doses de vinho circulam entre os membros. De um tempo a outro, alguns homens precisam urinar. Eles não hesitam em fazer isso em um canto do terreno. Nessas circunstâncias, percebo mais de um pedestre passando e observado o gesto. Em um determinado momento, uma senhora decide repreender Jacques, um dos homens do grupo, no momento em que ele terminara de urinar. Ela diz: "O que vocês estão pensando?! Por que vocês não usam os banheiros públicos como todo mundo?". "Banheiro público?!", grita Jacques, "onde a senhora está vendo um banheiro público?! Não tem nenhum banheiro público aqui perto!! E por que a gente tem que mijar como todo mundo quando todo mundo nos trata como se a gente fosse ninguém, como se a gente fosse um bando de animais?"

Como escreve Pierre Mayol, "sair na rua é correr o risco de ser reconhecido", de aderir a um sistema de valores e classificatório. Afinal, o corpo "serve de suporte para todas as mensagens gestuais que articulam essa conformidade: ele é um quadro negro onde se inscreve - e portanto se torna visível - o respeito aos códigos e a distanciação em relação ao sistema de comportamentos" (Mayol 1994: 27, tradução minha). Nesse sentido, toda atividade realizada "fora de lugar" contribui a "estigmatizar" e a "desqualificar" os moradores de rua como indivíduos, como diria Erving Goffman (2000), mas sobretudo a justificar por que eles são plenamente aceitos pela sociedade.

Com efeito, dormir na calçada ou embaixo de uma ponte, urinar sobre a via pública, atravessar a cidade em roupas usadas ou mesmo se alimentar em centros de distribuição são práticas não apenas desgastantes, mas que podem depreciar moralmente o indivíduo e colocar em risco "as expectativas ligadas à dignidade, à honra e a integridade próprias" (Honneth 2006: 192, tradução minha). Portanto, o universo da rua não se restringe a uma luta pela sobrevivência e contra as dificuldades de ordem material. Do ponto de vista das pessoas pesquisadas, viver na rua em Paris é sobretudo uma luta contra essa "precariedade que se lê na aparência das pessoas", como diz Gisèle Dambuyant-Wargny (2006: 19, tradução mina). Assim, o universo da rua se reveste de uma outra forma de luta; uma luta não mais pela sobrevivência, mas contra o "desrespeito social"13. 
Mas como caracterizar tais lutas contra o desrespeito social? Na obra de Axel Honneth (2006, 2009), a noção de desrespeito social aparece como a contrapartida negativa àquilo que o autor denomina de "reconhecimento social". Segundo o autor, "o indivíduo aprende a se apreender a si mesmo como possuindo um valor próprio e como sendo um membro específico da comunidade social na medida em que ele se assegura progressivamente de capacidades e necessidades específicas que o constituem enquanto pessoa, e isso graças às reações positivas que ele encontra em relação com os seus parceiros de interação." (Honneth 2006:134, trad. minha). Se cada sujeito humano é dependente de um contexto de relações sociais organizado a partir dos princípios normativos do reconhecimento recíproco, "o desaparecimento das relações de reconhecimento resulta em experiências de desprezo e humilhação que não passam sem consequências para a formação identitária do indivíduo." (Honneth 2006:134, trad. minha).

Marcadas materialmente e simbolicamente por suas lutas cotidianas pela sobrevivência, as pessoas estudadas incorporam o peso de sua condição social. Tudo se passa como se elas não dispusessem de nenhuma forma de reconhecimento social positivo, nenhuma razão para ocupar e habitar os lugares públicos, nenhuma possibilidade de serem apreciadas socialmente em suas práticas cotidianas. Lutar contra o desprezo social, do ponto de vista das pessoas estudadas, significa combater o peso de uma condição social marcada por experiências de humilhação, maus-tratos e rejeição social.

O "corpo precário", transformado pelas condições sociais de existência, ilustra bem esse combate cotidiano contra as situações de desprezo social, pois ele vai de encontro aos valores cardinais do "corpo moderno", segundo David Le Breton (1998): a saúde, a juventude, a sedução, a leveza e a higiene (Le Breton 1998:138, tradução minha). Valores que contribuem para definir as maneiras de ser e de se apresentar no universo social e, no caso das situações observadas durante a pesquisa de campo realizada em Paris, para julgar e moralizar as pessoas em situação de rua. Nesse sentido, restava a elas a possibilidade de reproduzir o binômio clássico dividindo os "bons pobres" dos "maus pobres": no primeiro caso, fazer de tudo para apagar as marcas corporais de uma vida passada na rua e mostrar-se apto ao trabalho; no segundo, abandonar-se à precaridade e, assim, aproximar-se definitivamente da figura típica do clochard $^{14}$.

Afinal, como conjurar as expectativas sociais relativas a um corpo maltratado pela rua considerando as dificuldades práticas para sobreviver à miséria? O que é preciso fazer para escapar ao sentimento de desrespeito social?

Durante a pesquisa etnográfica realizada em Paris, a melhor resposta a tais questões foi formulada a partir de um evento atípico: a manifestação dos Filhos de Dom Quixote durante o inverno de 2006, quando cerca de 200 pessoas, dentre as quais $130 S D F$, se tornaram sujeitos de uma disputa social e política em torno do direito à moradia. Nesse "tempo de desvio possível" próprio a uma manifestação (Fillieule \& Tartakowsky 2008:12, tradução minha), as lutas cotidianas de uma pessoa vivendo da rua tornam-se objeto de apreciação de um "público"15 interessado não mais em criticar o "corpo precário" e em rejeitar toda forma de habitação irregular dos espaços urbanos, mas em compreender como é possível que ainda existam pobres na França, país colocado entre as maiores economias do mundo e considerado como a "terra dos direitos humanos"16. 


\section{DO DESPREZO AO RECONHECIMENTO SOCIAL: O CASO DOS FILHOS DE DOM QUIXOTE}

Durante dois anos de pesquisa de campo em Paris, meu primeiro campo de interesse focou as lutas pela sobrevivência de pessoas que encontrei vivendo nas ruas da capital francesa. A fim de compreender a visibilidade social dessas lutas, interessei-me pelas transformações impressas nos corpos dessas pessoas em razão das suas condições materiais de existência. Rapidamente percebi como o peso social desse "corpo precário" repercute negativamente nos demais cidadãos; dei-me por conta também que cada esforço realizado por aquelas pessoas no sentido de apagar as marcas corporais de uma vida na miséria representava um esforço de neutralização do desprezo social experimentado no cotidiano. Tomar uma ducha, desodorizar-se com perfumes, lavar as roupas, alimentar-se bem e procurar ajuda médica visando a cura de ferimentos leves ou graves são gestos que se inscreviam em uma luta mais ampla contra os efeitos simbólicos do desprezo social.

Porém, apesar de todas as atividades cotidianas visando a reabilitação física e moral - isto é, do "eu"17 _ jamais as pessoas que estudei foram apreciadas de maneira positiva pelos demais habitantes de Paris. A única circunstância em que elas conseguiram ser reconhecidas socialmente como verdadeiras cidadãs foi durante um evento incomum, tornado possível por um grupo de amigos autodenominados Les Enfants de Don Quichotte, literalmente "Os Filhos de Dom Quixote", o anti-herói do célebre livro de Miguel de Cervantes. De maneira original, o grupo teve a ideia de convidar os parisienses para dormir uma noite em tendas colocadas em uma região visível de Paris. Seu objetivo era sensibilizar a opinião pública frente às dificuldades materiais de uma noite passada na rua durante o inverno parisiense. Com o tempo, porém, dezenas de pessoas em situação de rua passaram a ocupar as tendas, protagonizando assim uma mobilização coletiva. Mais importante ainda: com a presença da mídia e o apoio dos habitantes do bairro, elas assumiram uma nova identidade social: a de cidadãos franceses lutando por seus direitos fundamentais.

A fim de compreender como se deu tal transformação identitária, analisemos por um instante o desenvolvimento da mobilização. Tudo começa na manhã do dia 17 de dezembro de 2006. Os manifestantes, liderados por Augustin Legrand, 32 anos, contador de formação e ator de profissão, começam a instalar cem tendas vermelhas ao longo do canal Saint-Martin, zona norte de Paris. Em alguns minutos, o acampamento é implantado. A imprensa, contatada alguns minutos antes pelo grupo, não tarda a chegar. A polícia hesita e não reage - conta-se que a proximidade do canal serviu como "escudo" contra as ações repressivas, visto que os manifestantes poderiam se jogar na água e acusar a polícia de abuso de autoridade. $\mathrm{O}$ cenário está montado. Nos dias que seguem, Augustin Legrand tomou a palavra e denunciou com veemência a irresponsabilidade dos poderes públicos frente às condições de vida dos $S D F$ parisienses, como mostra a seqüência que transcrevo abaixo:

Sequência 3: 20 de dezembro de 2006, canal Saint-Martin em Paris. Eu me encontro no cais de Valmy, lado sudeste do canal, e percebo um grupo de pelo menos vinte pessoas se movimentando rapidamente. Nos arredores, várias câmeras de televisão, microfones e holofotes. Ao centro, vejo um homem alto e magro - um "gaillard", como se 
diz na França. Descubro se tratar de Augustin Legrand, o líder carismático dos Filhos de Dom Quixote. Ao me aproximar do grupo, começo a gravar suas palavras. Ele diz: "As pessoas que estão aqui eram pessoas como vocês, como eu, que tinham uma família e um apartamento. Mas, em um determinado momento, a 'porta bateu' e eles perderam tudo. E quando a 'porta bateu', eles passaram a viver na calçada da frente. [Quando isso acontece com uma pessoa], é ainda pior do que perder um apartamento ou a família. Na rua, é impossível de se curar [de uma doença ou de um machucado]. É impossível de se recuperar na França quando a gente é SDF. É isso que é preciso que os franceses entendam. (...). Eu espero que dezenas de franceses desçam às ruas. Tudo que precisamos é que a imprensa informe os franceses. (...). A gente quer que os franceses compreendam. Se eles compreenderem, a gente vai ter um plano Marshall da miséria. A Esquerda e a Direita se reunirão e vão desbloquear muito dinheiro. Nós teremos uma verdadeira oferta de soluções adaptadas de moradia para todas essas pessoas. Se as pessoas compreenderem, elas virão. E se elas compreenderem aquilo pelo que passam os SDF no dia-a-dia, elas vão lutar com a gente. (...). Se nós pegarmos a Convenção de Genebra, o Estado seria condenado uma centena de vezes por tortura. A gente trata os SDF pior do que eram tratados os prisioneiros de guerra. Higiene alimentar, condições de saúde, condições de sono, a insegurança, a saúde dos enfermos... A gente seria condenado, merda! E não se trata de prisioneiros de guerra. São cidadãos franceses!!!".

Além do cenário, das tendas, do mise en scène, o discurso dos Filhos de Dom Quixote se apoiou num certo "miserabilismo" (Grignon \& Passeron 1989), isto é, na dramatização da penúria e da dependência simbólica dos ditos SDF em relação aos "franceses". Porém, tal discurso miserabilista servindo para a construção de um "entendimento natural dos elementos a serem combatidos" (Gaboriau \& Graeff 2007) não seria facilmente sustentada no local da manifestação - ou, mais precisamente, pelas pessoas em situação de rua participando ativamente do movimento coletivo.

Por exemplo, durante minhas primeiras incursões de campo no local da manifestação, percebi a insurgência daquilo que Cláudia Girola (1996) denominou "histórias de perdas". Assim como as pessoas que ela encontrou vivendo na rua em Paris, os SDF acampando nas margens do canal Saint-Martin faziam questão de contar aos passantes e jornalistas os dramas vividos em suas trajetórias individuais e as violências experimentadas no cotidiano da rua. "Eu perdi o emprego e comecei a beber"; "A rua mata”; "Quando tu tá na rua, tu não é mais um ser humano". Desemprego, morte de um ente querido, alcoolismo, desprezo: durante a mobilização dos Filhos de Dom Quixote, essas temáticas tinham por objetivo atestar as violências consideradas típicas da situação de rua.

Mas falar das dores do passado não parecia suficiente para as pessoas engajadas na luta coletiva. Além de palavras, era preciso mostrar os corpos violentados pela miséria. Assim, de um lado a outro do acampamento, era possível ver manifestantes mostrando a pele calejada pelo frio e pela falta de higiene ou as chagas tidas como características de uma população cujo acesso à saúde é difícil. Com efeito, o líder do movimento, Augustin Legrand, compreendeu rapidamente a importância simbólica do corpo precário. Após ele mesmo haver passado algumas semanas na rua, ele fazia questão de apresentar suas mãos aos jornalistas e câmeras de televisão, dizendo: “Vejam as minhas mãos!! Vejam como elas estão usadas pela miséria!! E eu passei apenas três semanas na rua!!". 
Como o passar do tempo, na medida em que a manifestação se transformava em acampamento duradouro, o uso do corpo e das "histórias de perdas" ganharam um caráter cada vez mais instrumental. Para os SDF engajados na ação, era preciso contrapor o caráter miserabilista dos sofrimentos ressentidos no passado e no presente com uma certa virilidade populista. A coerência da ação coletiva passou a depender não apenas do ato de narrar as peripécias vividas e mostrar na pele os sofrimentos vividos, mas da disposição em mostrar-se apto a superar às dificuldades cotidianas do acampamento e de inverter o processo de incorporação dos efeitos da rua. Para fazer prova dessa virilidade populista, os $S D F$ manifestantes procuravam diminuir ou acabar com o consumo de álcool, organizar as tendas e garantir a higiene dos espaços públicos, além de se voluntariar para expurgar qualquer sinal de violência no interior dos locais da manifestação.

Ou seja: ao mesmo tempo em que um $S D F$ militante devia mostrar a fraqueza de seu corpo, ele precisava demonstrar uma capacidade de resistência física às dificuldades cotidianas e aos sintomas de abstinência ligados à redução ou ao abandono do consumo de álcool. Ao mesmo tempo em que os Filhos de Dom Quixote narravam os sofrimentos e revelavam os sofrimentos da vida na rua, eles procuravam mostrar uma fortaleza de caráter sem igual. Afinal de contas, visto que seu objetivo era dispor de formas de reconhecimento social positiva e, desde então, de formas de viver mais dignas, nenhum manifestante podia dar-se ao luxo de apresentar sua miséria de maneira definitiva. A precariedade como marca do passado e do universo da rua, a força e a resistência como sinais de um futuro promissor: essa era a lógica organizando as práticas de cada $S D F$ instalado ao longo do canal Saint-Martin, de cada militante lutando coletivamente contra o desprezo social e pela cidadania.

Conjugando-se a apresentação de "histórias de perdas" e de corpos maltratados pelas condições de vida miseráveis ao "cuidado de si", os Filhos de Dom Quixote conseguiram sensibilizar a opinião do público e a dos governantes. O movimento ganhou o apoio de repórteres independentes e de personalidades, como os candidatos à presidência da república François Bayrou e Segolène Royal, e o ator Jean Rochefort. Jornais da Alemanha, Inglaterra e Espanha noticiaram a ação do grupo e da família Legrand. Em 8 de janeiro, quatro semanas após o início do acampamento, a vitória foi proclamada: o Estado anunciou um pacote de medidas, incluindo 27.000 novas vagas de urgência em albergues e hotéis sociais (para além das 13.500 existentes em Paris) e um projeto de lei para fazer da moradia um direito de todos os cidadãos franceses.

Concretamente, para os 269 SDF que acamparam ao longo do canal, foram prometidas vagas "adaptadas às necessidades individuais". Um recenseamento foi realizado para conhecê-las. A partir da análise dos critérios utilizados pela Federação Nacional das Associações de Acolhimento e Reinserção Social (Fnars) da França, organismo responsável pelo recenseamento, a seleção e formulação de "propostas adaptadas de moradia" contribuiu para dividir os manifestantes em quatro categorias: 1) os $S D F$ dispondo de um emprego estável (rapidamente enquadrados, tais pessoas foram as únicas a receber propostas concretas de moradia); 2) os SDF em condições de trabalhar, isto é, considerados fisicamente e psicologicamente aptos a pleitear um emprego (neste caso, as pessoas eram encaminhadas para albergues sociais e hotéis, onde elas poderiam dispor de um endereço provisório até a obtenção de uma oportunidade de emprego); 3) as pessoas ditas "dessocializadas" 
(desocialisées, em francês), às quais seria preciso "reensinar" a morar antes de encaminhá-las para um emprego ou para um albergue social (nesse caso, criaram-se vagas específicas junto a instituições filantrópicas, às quais caberia o processo de reeducação); 4) os clochards, isto é, os casos considerados irrecuperáveis (para esses indivíduos, nenhuma "proposta adaptada" foi feita, salvo a internação num hospital psiquiátrico).

Frente aos resultados do recenseamento, os $S D F$ manifestantes se dividiram no último período da manifestação. Muitos procuraram ser incluídos nas categorias recenceadas, mas pelo menos $25 \%$ dos manifestantes não aceitaram as "soluções adaptadas" propostas pelo governo. Como disse um de meus interlocutores durante a mobilização, "a gente não quer propostas adaptadas. A gente quer uma moradia!". Ora, se coletivamente os manifestantes passaram a ser reconhecidos como cidadãos lutando por seus direitos, por que esse reconhecimento não foi suficiente para uma distribuição igualitária das vagas em apartamentos, albergues sociais e hotéis? Por que, ao final da mobilização, um quarto dos participantes encontraram-se, novamente, em situação de desprezo social?

\section{CONCLUSÃO}

A luta coletiva dos Filhos de Dom Quixote está na origem de modificações significativas na construção de objeto de estudo etnográfico realizada por mim em Paris. Antes da manifestação, minha pesquisa junto a essa população enfocava um quadro heterogêneo de situações de desprezo social e precariedade material. Até então, eu interessava-me pelo dia-a-dia dos meus interlocutores, por suas dificuldades relativas à domesticação do espaço urbano e ao cuidado com o corpo e a saúde. Após os eventos ocorridos durante o inverno de 2006 em Paris, uma questão de ordem simultaneamente subjetiva e social colocou-se: para uma pessoa em situação de rua, como é possível conjurar as expectativas sociais negativas que pesam sobre seu corpo precário e sobre suas atividades cotidianas? Será que a vida na rua, mais que uma luta pela sobrevivência, pode ser definida como uma luta contra o desprezo social? Se sim, como é possível neutralizar a experiência de desprezo ressentida pelas pessoas que se encontram em situação de rua?

Como tentei mostrar neste artigo, os SDF que participaram ativamente da mobilização dos Filhos de Dom Quixote tiveram a oportunidade de abandonar temporariamente - e, em alguns casos, definitivamente - a condição de desprezo social. Durante a manifestação, elas puderam dar visibilidade às condições de vida que explicam, ao menos em parte, o caráter precário de sua aparência e as dificuldades que elas enfrentam para sair da rua, inscrevendo-se dessa forma num "percurso de reconhecimento" (Ricoeur 2004). Nesse sentido, tais pessoas tiveram acesso a repertórios de práticas e discursos "legítimos" (Weber 1992): suas declarações sobre as condições de vida na rua foram escutadas, a precariedade de seus corpos foi tomada como resultado de determinantes de ordem coletiva e suas formas de habitar o espaço urbano foram consideradas como intoleráveis pelo governo. 
Porém, isso não foi suficiente para transformar substancialmente o sistema de representações que organiza a posição social ocupada por essas pessoas. Em linhas gerais, apenas aquelas que se mostraram capazes de abandonar a rua, rejeitando-a como universo simbólico e como modo de resistência ${ }^{18}$, foram recebidas com propostas concretas de moradia. Quanto aos outros, restou o abandono e o desprezo social.

Não obstante essa incapacidade de transformar definitivamente as formas de estima social relativas às pessoas em situação de rua, a luta dos Filhos de Dom Quixote contribuiu para tornar visível alguns dos determinantes sociais e simbólicos que organizam as reações negativas frente a essa condição social. Hospitalidade de um público sensível às reivindicações do movimento; exaltação de uma "pobreza dócil", segundo a qual é preciso evitar o consumo excessivo de álcool independentemente das condições psicossociais nas quais uma pessoa vivendo na rua se encontra; acusações de "preguiça" e de "falta de vontade" visando os manifestantes incapazes de respeitar a virilidade populista que, por diversas vezes, organizava as relações entre os membros do acampamento. Tais situações, identificadas durante a pesquisa de campo realizada em Paris, participam das "hierarquias de valor socialmente institucionalizadas" que, segundo Axel Honneth (2009), dão o tom das experiências de desprezo social vividas por milhares de homens, mulheres e crianças tanto em países "ricos" como em países "pobres". 


\section{NOTAS}

1 Riqueza e pobreza não são noções unívocas, seja no vocabulário corrente ou no especializado. Para Philippe Sassier, "as reflexões sobre a pobreza refletem menos a condição real dos pobres que os aspectos da vida considerados em cada época como seu infortúnio. No final das contas, o olhar postado sobre o pobre não faz nada além do que colocar em evidência o que parece estar faltando à comunidade." (Sassier 1990:379). Segundo Marshall Sahlins, "a pobreza não consiste em uma reduzida quantidade de bens, nem simplesmente em uma relação entre meios e fins; trata-se, antes de tudo, de uma relação de homem a homem, um statut social." (Sahlins 1976:80).

2 "Os programas sociais desenvolvidos [no contexto de rua] trazem a marca ideológica do descarte social de uma população que é tratada como excedente. São programas marcados pela institucionalização de práticas que visam à retirada dessas pessoas das ruas, oferecendo, entretanto poucas possibilidades de uma reestruturação de suas vidas." (Varanda \& Adorno 2004:66).

3 "Quantos dentre nós, em meio às atividades corriqueiras, nos deparamos com a figura de um morador de rua? (...). Alguns as vêem como perigosas, apressam o passo. Outros logo as consideram vagabundas e que ali estão por não quererem trabalhar, olhando-as com hostilidade. Muitos atravessam a rua com receio de serem abordados por pedido de esmola, ou mesmo por pré-conceberem que são pessoas sujas e mal cheirosas. Há também aqueles que delas sentem pena e olham-nas com comoção ou piedade. Enfim, é comum negligenciarmos involuntariamente o contato com elas. (...). Observa-se, assim, a existência de representações sociais pejorativas, em relação à população em situação de rua, que se materializam nas relações sociais. Vagabundo, preguiçoso, bêbado, sujo, perigoso, coitado, mendigo... São designações comuns dirigidas às pessoas em situação de rua." (Mattos \& Ferreira 2004:47).

4 Além de administrativa - trata-se de uma categoria formulada pela polícia parisiense no final do século XIX (Gaboriau 1998), a denominação Sans Domicile Fixe (SDF) é corriqueira quando se trata de denominar as pessoas que, não dispondo de meios necessários para o acesso a uma forma de moradia, passa uma parte mais ou menos considerável de sua existência na rua - o que não é o caso, por exemplo, daquelas que vivem em barracos insalubres. Para os fins do presente artigo, tratarei meus interlocutores que não se encontravam na manifestação dos Filhos de Dom Quixote como "moradores de rua" e guardarei o termo SDF para aqueles que dela participaram, visto que se trata de uma denominação usada pelos próprios manifestantes. Isso dito, vale a pena sublinhar que as formas de categorizar e denominar determinados agrupamentos de pessoas não é sem consequência no mundo social. Como propõe Hervé Le Brás, "definir uma população é um golpe de força [coup de force]: a um conjunto de indivíduos impõe-se uma categoria que irá desde então lhes catalogar e, eventualmente, condicionar sua ação." (Le Bras 2000, p. 7).

5 Utilizei o rio Sena como ponto de partida para minha pesquisa etnográfica por duas razões: primeiro, por servir como ponto de referência fixo para minhas caminhadas cotidianas; segundo, porque algumas dezenas de moradores de rua viviam às margens do rio na época em que iniciava a minha pesquisa.

6 Entre as cinquenta e uma pessoas pesquisadas, apenas onze disseram manter contatos fortuitos com a família e amigos. Quanto às outras, era comum evitar toda comunicação com os próximos a fim de ocultar as condições miseráveis de vida nas quais elas se encontravam.

7 Ainda que seja corriqueiro afirmar que a maioria da população de rua na França seja de origem estrangeira, isso não se verifica na prática de pesquisa. No caso da minha amostra, menos de $15 \%$ das pessoas não eram francesas. Uma pesquisa realizada pelo INED (Institut National d'Études Demographiques) apontou em cerca de 45\% a proporção de pessoas estrangeiras frequentando albergues e locais de distribuição de alimentos e refeições gratuitas (Marpsat 2002). Isso dito, o fato de ser estrangeiro ou imigrante ilegal na França está entre os "fatores de risco" relacionados à pobreza naquele país (cf. Thave 1999) .

8 Isso sem mencionar as "técnicas de prevenção situacional" cada vez mais presentes na vida dos parisienses, cujo objetivo imediato é tornar difícil ou mesmo impossível a instalação durável das pessoas no espaço público. Sobre a sazonalidade das práticas repressivas, ver Terrolle (2004). No que diz respeito às técnicas de prevenção situacional, sugiro a leitura do guia publicado por Michel Le Calloch para a Direção de Segurança e Prevenção da cidade de Lyon/FR (Le Calloch 2002).

9 As violências no universo da rua são de várias ordens - elas são físicas, quando se trata, por exemplo, de espancamentos e estupros sofridos e perpetuados por moradores de rua; são simbólicas ao reiterar dominação social ou ao contribuir para a interiorização do desprezo social. Sobre essas temáticas, ver Ballet (2005), Gaboriau e Terrolle (2003) e Pichon (2007). 
10 A primeira formulação dessas "sequências etnográficas" me foi proposta por Patrick Gaboriau, meu orientador de doutorado na França. Eu as utilizei durante o processo de escrita de uma tese intitulada "De la survie à la reconnaissance: ethnologie de personnes 'sans logis' à Paris" (Graeff 2010). O formato outrora utilizado pareceu-me pertinente para a organização do presente artigo, pois ele permite uma articulação fluida entre a argumentação e a apresentação dos dados da pesquisa.

11 Os nomes utilizados ao longo do texto são fictícios.

12 Segundo Erving Goffman (2000), o termo "estigma" foi criado pelos gregos para "designar sinais corporais com os quais se evidenciava alguma coisa de extraordinário ou mau sobre o status moral de quem os apresentava" (p. 11). Na era cristã, ao termo foram acrescentadas duas metáforas: 1) sinais corporais de graça divina; e 2) sinais corporais de distúrbios físicos. No texto, o termo designa um tipo especial de relação entre um atributo profundamente depreciativo e o estereótipo (o padrão definido socialmente). Ainda segundo Goffman, existem pelo menos três tipos de estigma: 1) abominações no corpo; 2) culpas de caráter individual (percebidas como fraqueza de caráter); e 3) estigmas tribais de raça, nação e religião. Por definição, um estigmatizado não é completamente humano (i.e., normal). Se não é humano, os normais criam uma série de teorias sobre a condição do estigmatizado (uma ideologia para explicar a sua inferioridade), bem como surgem denominações "comuns" para cada condição (aleijado, bastardo, leproso, retardado etc.). A partir de um estigma, são associados outras imperfeições (além da original, com tratar um cego como um aleijado) e, ao mesmo tempo, alguns atributos desejáveis (como sexto sentido ou percepção especial). Além disso, há uma tendência dos normais interpretarem qualquer defesa do estigmatizado como uma expressão direta de seu defeito (um ex-presidiário que se enfurece é diferente de um empresário que se enfurece). Sobre o estigma que pauta os gestos, corpos e atividades das pessoas em situação de rua, ver as teses de Cláudia Turra Magni (2006) e, mais recentemente, de Simone Miziara Frangella (2004). No contexto internacional, ver por exemplo as pesquisas de Patrick Gaboriau (1990), de Samira Kawash (1998) e de Gisèle Dambuyant-Wargny (2006).

13 Uma das dimensões do "desprezo social" é o sentimento de humilhação "que passa pela própria consciência que o pobre faz de si mesmo, como se a sua condição de pobreza fosse resultado somente desse processo", segundo as discussões propostas por Antonio Euzébios Filho e Raquel Souza Lobo Guzzo num artigo sobre desigualdade social e pobreza. (Filho \& Guzzo 2009:42). Essa "visão internalista", segundo a expressão dos autores, é uma das dimensões do conceito de "violência simbólica" proposto por Pierre Bourdieu (1994). Para o sociólogo francês, a violência simbólica é uma forma de dominação que se baseia em submissões sucessivas que não são percebidas como tal - e cuja força reside exatamente nesse "consentimento da dominação" (Bourdieu 1994).

14 O clochard é uma figura típica da pobreza na França. De um ponto de vista imaginário, ele se aproxima da figura do mendigo no Brasil - alcoólatra, bom vivant ou preguiçoso, despreocupado com a higiene corporal e a aparência, e geralmente inofensivo (tal como a figura do mendigo, o clochard pode ser acusado de mendigar de forma agressiva).

15 A categoria "público" é controversa em Ciências Sociais. No contexto do presente artigo, compreenda-se por "público" os observadores, espectadores de televisão e leitores de jornal, assim como as pessoas presentes no local da manifestação que não integravam o movimento social.

16 Expressão recolhida junto a manifestantes no local da manifestação.

17 A definição de "eu" ou de "ego" (self) utilizada neste trabalho segue àquela proposta por Erving Goffman em seu livro "A representação do eu na vida cotidiana", a saber uma construção social negociada de maneira sistemática pelos atores em situações concretas de interação social. Ou, como escreveu Heliana de Barros Conde Rodrigues (Costa \& Rodrigues 2007), "para Goffman, o próprio simesmo ou self (que não se confunde com o eu-evidência do individualismo, tampouco com o sujeito das filosofias da consciência, mesmo que fenomenológicas) é uma resultante da interação".

18 De acordo com Danichi Hausen Mizoguchi, Luis Artur Costa e Manoel Luce Madeira, os moradores de rua ocupam uma posição subversiva per se, isto é, segundo a proposição dos autores, "a resistência espacial é tida como a própria maneira do morador de rua habitar a urbe - seja como morador, seja como vendedor -, ou seja, a reinvenção dos desvalidos vãos da cidade." (Mizoguchi, Costa \& Madeira 2007:38). 


\section{REFERENCIAS BIBLIOGRAFICAS}

BALLET, D. 2005. Les SDF : visibles, proches, citoyens. Paris: PUF.

BOURDIEU, P. (1994). Raisons pratiques. Sur la théorie de l'action. Paris : Seuil.

COSTA, Marcio José de Araújo \& RODRIGUES, Heliana de Barros Conde. 2007. "Dramaturgia Social de Goffman e dramatização deleuze-guattariana: problematização pertinente ou mero quiproquó?". Anais do XIV Encontro Nacional da ABRAPSO-CD-rom. Rio de Janeiro: ABRAPSO.

DAMBUYANT-WARGNY, G. 2006. Quand on n'a plus que son corps. Paris: Armand Collins.

ECKERT, C. 1998. "Questões em torno do uso de relatos e narrativas biográficas na experiência etnográfica". Revista Humanas 19: 94-97.

FILHO, A. E. \& GUZZO, R. S. L. 2009. "Desigualdade social e pobreza: contexto de vida e de sobrevivência". Psicologia \& Sociedade 21(1): 35-44.

FILLIEULE, O. \& TARTAKOWSKY, D. 2008. La manifestation. Paris: Les Presses de Sciences Po.

FRANGELA, Simone. 2004. Corpos Urbanos Errantes: uma etnografia da corporalidade de moradores de rua em São Paulo. Tese de doutorado. São Paulo: Unicamp.

GABORIAU, Patrick. 1990. Clochard. L'univers d'un groupe de sans-abri parisiens. Paris: Julliard.

Desclée

1998. SDF à la Belle Epoque. L'univers des mendiants vagabonds au tournant des XIX et XX siècles. Paris:

2004. "Mettre les questions à la question. Travail de terrain et raisonnement sur les " sans-logis ". Espaces et sociétés 116-117: 111-123.

\& TERROLLE, D. 2003. Ethnologie des Sans-Logis. Étude d'une forme de domination sociale. Paris: L'Harmattan.

GABORIAU, Patrick \& GRAEFF, Lucas. 2007. "Une lutte collective : 'Les Enfants de Don Quichotte'. Neuf tentatives de construction narrative". Journal des Anthropologues 110: 245-254.

GIROLA, Claudia. 1996. "Rencontrer des personnes sans abri. Une anthropologie réflexive". Politix 9(34): 87-98.

GOFFMAN, E. 2000. Estigma: notas sobre a manipulação da identidade deteriorada. Rio de Janeiro: LTC.

GRAEFF, L. 2002. “Representações Sociais da Aposentadoria”. Textos sobre Envelhecimento 4(7): 19-34.

2007. "Instituições totais e a questão asilar: uma abordagem compreensiva". Estudos interdisciplinares sobre o envelhecimento 11: 9-27.

2010. De la survie à la reconnaissance: ethnologie de personnes "sans logis" à Paris. Tese de doutorado. Université de Paris 5, Paris, França.

GRIGNON, Claude \& PASSERON, Jean-Claude. 1989. Le savant et le populaire: misérabilisme et populisme en sociologie et en littérature. Paris: Seuil. 
HONNETH, A. 2006. La société du mépris. Vers une nouvelle Théorie critique. Paris: La découverte. 2008. "Reconnaissance et reproduction sociale". In PAYET, J-P. BATTEGAY, A. (orgs.) La reconnaissance à l'epreuve, explorations socio-anthropologiques. Lille: Septentrion. 2009. Luta por reconhecimento: a gramática moral dos conflitos sociais. São Paulo: Ed. 34.

KAWASH, Samira. 1998. "The Homeless Body". Public Culture Winter 10(2): 319-339, 1998

LE BRAS, Hervé. 2000. L'invention des populations: Biologie, idéologie et politique. Paris: Odile Jacob.

LE BRETON, D. 1998. Anthropologie du corps et modernité. Paris : PUF.

LE CALLOCH, M. 2002 Prévention de la malveillance par l'urbanisme et la conception des bâtiments. Guide à I'usage des chefs de projets. Ville de Lyon, Direction de la Sécurité et de la Prévention Cellule de coordination du Contrat Local de Sécurité.

MAGNI, Claudia Turra. 2006. Nomadismo Urbano: uma etnografia sobre moradores de rua em Porto Alegre. Sta Cruz do Sul: EDUNISC.

MALINOWSKI, Bronislaw. 1976. Argonautas do pacifico ocidental: Um relato do empreendimento e da aventura dos nativos nos arquipélagos da Nova Guiné Melanésia. São Paulo: Abril Cultural.

MARPSAT, M. 2002. "Les personnes sans domicile à Paris : Les résultats du programme de rechcerche de l'INED”. European Population papers $n^{\circ} 3$, Strasbourg, Council of Europe.

MATTOS, R. M., FERREIRA, R. F. 2004. “Quem vocês pensam que (elas) são? Representações sobre as pessoas em situação de rua". Psicologia e Sociedade 16(2): 47-58.

MAYOL, P. 1994. “Habiter”. In DE CERTEAU, M. (org.) L'invention du quotidien 2. Habiter, cuisiner. Paris : Gallimard. MIZOGUCHI, D. H.; COSTA, L. A. \& MADEIRA, M. L. 2007. “Sujeitos no sumidouro: a experiência de criação e resistência do jornal boca de rua". Psicologia \& Sociedade 19(1): 38-44.

PICHON, P. 2007. Vivre dans la rue. Sociologie des sans domicile fixe. Paris: Aux lieux d'être.

RICOEUR, O. 2004. Parcours de la reconnaissance. Paris: Editions Stock.

SAHLINS, M. 1976. Age de pierre, âge d'abondance. Paris: Gallimard.

SASSIER, P. 1990. Du bon usage des pauvres. Histoire d'un thème politique (XVIe-XXe siècle). Paris: Fayard.

TERROLLE, D. 2004. “La ville dissuasive : I'envers de la solidarité avec les SDF”. Espaces et sociétés 116-117.

THAVE, S. 1999 “Les étrangers et leurs logements". Insee-Première 689.

VARANDA, W. \& ADORNO, R. de C. F. 2004. “Descartáveis urbanos: discutindo a complexidade da população de rua e o desafio para políticas de saúde". Saúde e Sociedade 13(1): 56-69.

WEBER, M. 1992. Essais sur la théorie de la science. Paris: Plon. 


\section{Viver na rua em Paris: Do desprezo ao reconhecimento}

\section{RESUMO}

A partir de um estudo etnográfico realizado entre maio de 2006 a abril de 2008 em Paris, o autor descobre as dificuldades cotidianas, encontradas por pessoas em situação de rua, relativas à higiene, à ocupação de espaços urbanos e especialmente aos esforços realizados no sentido de encontrar formas de reconhecimento social marcadas pelo orgulho e pela estima social. Essas pessoas lutam contra o "desprezo social" de diferentes maneiras: algumas se instalam em recantos ou nas margens da cidade a fim de se tornarem menos visíveis, outras tentam apagar todas as marcas de precariedade de seus corpos, outras ainda se vinculam a uma manifestação como a dos Filhos de Dom Quixote durante o inverno de 2006, em Paris. Nesses percursos da sobrevivência ao reconhecimento, as experiências de viver na rua convidam a ver e a pensar algumas das hierarquias de valor socialmente institucionalizadas que caracterizam a sociedade francesa.

PALAVRAS-CHAVE: pobreza; situação de rua; corpo; sobrevivência; reconhecimento social.

\section{Living on the street of Paris: Between contempt and recognition}

\section{ABSTRACT}

The author uses an ethnographic investigation, made from May 2006 to April 2008 in Paris, to show the daily difficulties encountered by homeless people regarding their hygiene, the occupation of public places, and especially their efforts to have access to some forms of recognition marked by the pride and the social esteem. Those people fight against the "social contempt" in different ways: some of them settle down in "corners" or in the margins of the city to be less visible, others try to erase all forms of precariousness on their bodies, and others joined the manifestation of Childrens of Don Quixotte during the fall of 2006 in Paris. By walking these paths, from survival to recognition, these homeless people invite us to see and to think some of the hierarchies of values socially institutionalized which characterize French society.

KEYWORDS: poverty; homeless situation; body; struggle; survival; social recognition. 